\title{
Análise de rentabilidade de uma empresa com opção de comercialização de queijo ou leite
}

[Analysis of profitability in a production system with the option of commercializing cheese or milk]

\author{
M.A. Lopes $^{1}$, E.A. Carmo ${ }^{2}$, A.L.R. Lima ${ }^{3}$, F.M. Carvalho ${ }^{3}$ \\ ${ }^{1}$ Departamento de Medicina Veterinária - UFLA \\ Caixa Postal 37 \\ 37200-000 - Lavras, MG \\ ${ }^{2}$ Aluna de graduação - UFLA - Lavras, MG \\ ${ }^{3}$ Departamento de Administração e Economia - UFLA - Lavras, MG
}

\begin{abstract}
RESUMO
Por meio de simulações, compararam-se os dados de rentabilidade do sistema de produção de uma propriedade rural localizada em Nepomuceno, MG, considerando duas situações: a primeira, real, produz queijo, e a segunda, simulada, vende leite para o laticínio. A produção e a comercialização de queijo mostraram-se mais rentáveis que a comercialização do leite in natura, representando uma alternativa para o incremento da renda do produtor de leite.
\end{abstract}

Palavras-chave: leite, agroindústria, custo de produção, produção de queijo

\begin{abstract}
It was performed a simulation in order to compare the profitability of a cheese producer dairy farm, located in Nepomuceno city, Minas Gerais state. According to the simulation, data of the production system were compared in two different situations: cheese production (real) and selling milk to dairy. The cheese production and marketing was more profitable than milk selling, representing an alternative to increase the productor's income.
\end{abstract}

Keywords: dairy, agro-industry, production cost, cheese production

\section{INTRODUÇ̃̃̃O}

Dados obtidos da apuração dos custos de produção são utilizados para diferentes finalidades, como: estudo da rentabilidade da atividade leiteira, redução dos custos controláveis, planejamento e controle das operações do sistema de produção do leite, identificação e determinação da rentabilidade do produto, identificação do ponto de equilíbrio do sistema de produção de leite, e instrumento de apoio ao produtor no processo de tomada de decisões corretas (Lopes e Carvalho, 2000).

Recebido em 31 de agosto de 2004

Aceito em 7 de março de 2006

*Autor para correspondência (corresponding author)

E-mail: malopes@ufla.br

Apoio: FAPEMIG (SHA 80894/03)
A produção de leite e o seu processamento industrial são importantes atividades do estado de Minas Gerais. O estado é o maior produtor de leite e queijo do país (Sato, 1996). Estima-se que haja mais de 27.000 produtores de queijo artesanal, criando cerca de 26.870 empregos diretos (Empresa..., 2004). A maior parte dessa produção é proveniente de pequenas e médias queijarias e de propriedades rurais, que, além de produzirem o leite, transformam-no em queijo, agregando valor ao produto.

Considerando que não foram encontrados resultados de pesquisas sobre o assunto, decidiuse realizar este estudo, cujo objetivo foi simular uma situação para comparar a rentabilidade de uma propriedade produtora de leite que tem a opção de comercialização de queijo ou venda de leite in natura. 


\section{MATERIAL E MÉTODOS}

Os dados foram provenientes de um sistema de produção de leite localizado na região de Nepomuceno, sul do estado de Minas Gerais, coletados entre janeiro de 2002 e dezembro de 2003.

A pesquisa considerou duas etapas no levantamento das informações. $\mathrm{Na}$ primeira utilizou-se um questionário e uma caderneta de campo, para realizar o inventário completo dos bens da propriedade, apurando o valor e a vida útil de cada ativo, os quais foram alocados em um dos seguintes grupos: benfeitorias, máquinas, veículos, equipamentos e implementos, ferramentas e rebanho. Nas situações nas quais o pecuarista não dispunha de informações referentes ao valor e à data de aquisição para estimar o valor atual e a vida útil restante, foi utilizado o critério adotado por Lopes et al. (2004a). Quanto às benfeitorias, atribuiu-se um estado de conservação com o objetivo de auxiliar na estimativa do valor atual. Em função da área, do estado de conservação e do padrão de acabamento, estimou-se um valor por metro quadrado $\left(\mathrm{m}^{2}\right)$ de construção. $\mathrm{O}$ valor atual utilizado foi o produto do valor do $\mathrm{m}^{2}$ pela área da benfeitoria.

$\mathrm{Na}$ segunda etapa, a propriedade foi visitada no início de cada mês para coleta de dados referentes às produções, despesas realizadas $\mathrm{e}$ receitas apuradas no mês anterior. A coleta de dados deu-se em cadernetas de campo, especificamente preparadas para esse fim. Os dados foram cadastrados no software Custo Bovino Leite $^{\circledR}$ (Lopes et al., 2002), aplicativo utilizado para o processamento eletrônico dos dados, e a análise de rentabilidade dos sistemas de produção. O software contemplou as duas estruturas de custo de produção: custo total de produção, que envolve o custo fixo e variável, utilizada por Reis (1999) e custo operacional, proposta por Matsunaga et al. (1976).

Os itens que compõem o custo operacional efetivo de produção foram divididos em: mãode-obra, alimentação, sanidade, reprodução, ordenha, impostos, energia e despesas diversas (Lopes et al., 2004a). Nesta pesquisa, as despesas referentes aos insumos utilizados na fabricação do queijo foram separadas das despesas diversas, possibilitando um estudo mais detalhado.
Para evitar duplicidade de lançamento de despesas, a análise não considerou a depreciação de matrizes, uma vez que o sistema avalia o custo de produção da atividade como um todo e os custos de cria e recria de fêmeas de reposição, assim como os de manutenção de vacas secas (Lopes et al., 2004b). Utilizou-se o aplicativo MS Excel ${ }^{\circledR}$, visando facilitar as comparações, discussões e apresentações dos resultados por meio de tabelas.

Durante a estação seca do ano, os animais receberam, no cocho, alimentação concentrada, na proporção de $1 \mathrm{~kg}$ de ração para cada $3 \mathrm{a} 4 \mathrm{~kg}$ de leite, e volumoso, na forma de silagem de milho e cana-de-açúcar e/ou capim-elefante picados. Os animais tiveram acesso a pastagens, de condições bastante precárias, com praticamente nenhuma disponibilidade de alimentos. Na estação chuvosa, os animais foram suplementados com concentrado, nas mesmas proporções da estação seca, e a alimentação volumosa consistiu apenas de pastagens com forrageiras do gênero Brachiaria e/ou nativas (pastagens naturais).

A área do sistema de produção é de seis hectares, na qual estão cerca de $\mathrm{R} \$ 30.700,00$ e $\mathrm{R} \$ 3.000,00$ investidos em benfeitorias e equipamentos, respectivamente. A produção diária foi de, aproximadamente, $70 \mathrm{~kg}$ de leite tipo $\mathrm{C}$, utilizados na fabricação de queijo tipo muçarela. Tanto no sistema de produção de leite, quanto na produção de queijo, a mão-de-obra foi exclusivamente familiar.

\section{RESULTADOS E DISCUSSÃO}

Um resumo da análise de rentabilidade da produção nos anos 2002 e 2003 pode ser observado na Tab. 1. A receita total durante o período de estudo foi de $\mathrm{R} \$ 32.501,89$ e $\mathrm{R} \$ 40.093,00$, para a comercialização simulada do leite e para a produção do queijo, respectivamente, o que correspondeu à soma dos valores apurados com a venda do produto (leite ou queijo), animais e subprodutos (Tab. 2). A diferença entre as receitas deveu-se ao valor pago pelo $\mathrm{kg}$ do queijo (vendido a varejistas da cidade) e pelo $\mathrm{kg}$ do leite (vendido ao laticínio). $\mathrm{O}$ valor pago por $\mathrm{kg}$ de leite no primeiro ano da pesquisa, 2002, foi de $\mathrm{R} \$ 0,33$, enquanto a receita auferida, por $\mathrm{kg}$ de leite, após agregado o valor 
de fabricação de queijo, foi de $\mathrm{R} \$ 0,48$ (aumento de $45 \%$ ). No segundo período, a diferença foi de $31,8 \%$. A venda de animais contribuiu com cerca de $36 \%$ da receita total do sistema que comercializou leite in natura e de $30 \%$ para o sistema que comercializou queijo. Isso mostrou que o segundo foi menos dependente da venda de animais. Quanto à venda de subprodutos (esterco), sua comercialização foi eventual, justificando a pequena contribuição na receita bruta. Parte do subproduto foi utilizado como adubo orgânico em capineiras.

Tabela 1. Resumo da análise de rentabilidade, em R $\$$ (período de 24 meses), de acordo com o sistema de produção em uma propriedade leiteira

\begin{tabular}{|c|c|c|c|c|c|c|}
\hline \multirow{2}{*}{ Descrição } & \multicolumn{3}{|c|}{ Venda de leite in natura } & \multicolumn{3}{|c|}{ Comercialização de queijo } \\
\hline & 2002 & 2003 & Total & 2002 & 2003 & Total \\
\hline Receitas (R\$) & $13.754,59$ & $18.747,30$ & $32.501,89$ & $17.479,00$ & $22.614,00$ & $40.093,00$ \\
\hline Leite $(\mathrm{R} \$)$ & $8.104,20$ & $12.125,75$ & $20.229,96$ & $11.829,79$ & $15.994,88$ & $27.824,67$ \\
\hline Animais (R\$) & $5.450,94$ & $6.540,93$ & $11.991,88$ & $5.449,95$ & $6.539,97$ & $11.989,92$ \\
\hline Subprodutos (R\$) & 199,44 & 80,61 & 280,05 & 199,26 & 79,15 & 278,41 \\
\hline Custo operacional total (COT) & $13.230,77$ & $13.159,68$ & $26.390,45$ & $13.096,34$ & $13.107,48$ & $26.203,82$ \\
\hline Custo operacional efetivo (COE) & $8.937,64$ & $8.338,96$ & $17.276,60$ & $8.803,21$ & $8.286,76$ & $17.089,97$ \\
\hline Custo com depreciação & $1.893,13$ & $1.940,72$ & $3.833,85$ & $1.893,13$ & $1.940,72$ & $3.833,85$ \\
\hline Mão-de-obra familiar & $2.400,00$ & $2.880,00$ & $5.280,00$ & $2.400,00$ & $2.880,00$ & $5.280,00$ \\
\hline Custo total (CT) & $16.373,72$ & $16.287,94$ & $32.661,66$ & $16.236,78$ & $16.235,02$ & $32.471,80$ \\
\hline Custos fixos (CF) & $5.070,66$ & $5.131,82$ & $10.202,48$ & $5.070,66$ & $5.131,82$ & $10.202,48$ \\
\hline Remuneração da terra & $1.015,20$ & $1.000,74$ & $2.015,94$ & $1.015,20$ & $1.000,74$ & $2.015,94$ \\
\hline Remuneração do capital investido & $1.996,33$ & $2.024,36$ & $4.020,69$ & $1.996,33$ & $2.024,36$ & $4.020,69$ \\
\hline Impostos & 166,00 & 166,00 & 332,00 & 166,00 & 166,00 & 332,00 \\
\hline Depreciação & $1.893,13$ & $1.940,72$ & $3.833,85$ & $1.893,13$ & $1.940,72$ & $3.833,85$ \\
\hline Custos variáveis $(\mathrm{CV})$ & $11.303,06$ & $11.156,12$ & $22.459,18$ & $11.166,12$ & $11.103,20$ & $22.269,32$ \\
\hline Custo operacional efetivo (s/imp.) & $8.771,64$ & $8.172,96$ & $16.944,60$ & $8.637,21$ & $8.120,76$ & $16.757,97$ \\
\hline Mão-de-obra familiar & $2.400,00$ & $2.880,00$ & $5.280,00$ & $2.400,00$ & $2.880,00$ & $5.280,00$ \\
\hline Remuneração do capital de giro & 131,42 & 103,16 & 234,58 & 128,91 & 102,44 & 231,35 \\
\hline Margem bruta & $4.816,95$ & $10.408,34$ & $15.225,29$ & $8.675,79$ & $14.327,24$ & $23.003,03$ \\
\hline Margem líquida & 523,82 & $5.587,62$ & $6.111,44$ & $4.382,66$ & $9.506,52$ & $13.889,18$ \\
\hline Resultado (lucro ou prejuízo) & $2.619,13)$ & $2.459,36$ & $(159,77)$ & $1.242,22$ & $6.378,98$ & $7.621,20$ \\
\hline Margem bruta / kg leite & 0,19 & 0,38 & 0,57 & 0,35 & 0,52 & 0,87 \\
\hline Margem líquida / kg leite & 0,02 & 0,20 & 0,22 & 0,18 & 0,35 & 0,52 \\
\hline Resultado (lucro ou prejuízo) / $\mathrm{kg}$ leite & $(0,11)$ & 0,09 & $(0,02)$ & 0,05 & 0,23 & 0,28 \\
\hline Lucratividade (\%) & $-19 \%$ & $13 \%$ & $(0,06)$ & $7 \%$ & $28 \%$ & 0,35 \\
\hline Rentabilidade (\%) & $10,05 \%$ & $9,87 \%$ & 0,20 & $10,05 \%$ & $10,05 \%$ & 0,20 \\
\hline Quantidade de leite $(\mathrm{kg})$ & $24.868,00$ & $27.505,00$ & $52.373,00$ & $24.868,00$ & $27.505,00$ & $52.373,00$ \\
\hline
\end{tabular}

Tabela 2. Contribuição de cada item na receita, em \% (período de 24 meses), de acordo com o sistema de produção em uma propriedade leiteira

\begin{tabular}{lcccc}
\hline \multirow{2}{*}{ Descrição } & Ano & \multicolumn{2}{c}{ Venda de leite in natura } & \multicolumn{2}{c}{ Comercialização de queijo } \\
\cline { 3 - 5 } & 2002 & 2003 & 2002 & 2003 \\
\hline Venda do produto & $58,92 \%$ & $64,68 \%$ & $67,68 \%$ & $70,73 \%$ \\
Venda de animais & $39,63 \%$ & $34,89 \%$ & $31,18 \%$ & $28,92 \%$ \\
Venda de subprodutos & $1,45 \%$ & $0,43 \%$ & $1,14 \%$ & $0,35 \%$ \\
\hline
\end{tabular}

No sistema que comercializa o leite, o custo variável médio foi superior ao preço de venda do leite, no primeiro período, não permitindo que o sistema atingisse o ponto de equilíbrio. Esse índice evidencia que muitos esforços gerenciais e até mesmo tecnológicos devam ser feitos com o objetivo de aumentar as médias diárias de leite sem, contudo, aumentar o custo variável médio. Uma alternativa, segundo Lopes et al. (2004b), é aumentar a eficiência produtiva, ou seja, a produtividade por matriz, otimizando as despesas com mão-de-obra, alimentação com volumoso, medicamentos, impostos fixos e energia. 
O custo operacional total (COT) foi de $\mathrm{R} \$ 26.390,45$ e $\mathrm{R} \$ 26.203,82$, para o sistema que comercializa leite e o sistema de produção de queijo, respectivamente (Tab. 1). Houve pequena diferença entre as atividades, atribuída, principalmente, ao preço pago pelo transporte do leite e ao INSS, gastos que não ocorreram com o sistema de produção do queijo, embora neste exista a despesa com coalho como insumo da produção de queijo (Tab. 3). As receitas no período permitiram que fosse feita a reserva referente à depreciação e que se remunerasse a mão-de-obra familiar.

Tabela 3. Contribuição de cada item no custo operacional efetivo, em \% (período de 24 meses), de acordo com o sistema de produção em uma propriedade leiteira

\begin{tabular}{|c|c|c|c|c|}
\hline \multirow{2}{*}{ Descrição Ano } & \multicolumn{2}{|c|}{ Venda de leite in natura } & \multicolumn{2}{|c|}{ Comercialização de queijo } \\
\hline & 2002 & 2003 & 2002 & 2003 \\
\hline Mão-de-obra & 0,0 & 0,0 & 0,0 & 0,0 \\
\hline Alimentação & 76,20 & 78,32 & 77,36 & 78,82 \\
\hline Sanidade & 1,85 & 1,70 & 1,88 & 1,71 \\
\hline Inseminação artificial & 0,0 & 0,0 & 0,0 & 0,0 \\
\hline Ordenha & 0,0 & 0,0 & 0,0 & 0,0 \\
\hline Impostos (ITR e IPVA) & 1,86 & 1,99 & 1,89 & 2,00 \\
\hline Energia & 15,40 & 15,06 & 15,64 & 15,16 \\
\hline Insumos para queijo & 0,0 & 0,0 & 0,16 & 0,56 \\
\hline INSS do leite & 0,44 & 0,61 & 0,0 & 0,0 \\
\hline Despesas diversas & 4,69 & 2,31 & 3,07 & 1,75 \\
\hline Total & 100,00 & 100,00 & 100,00 & 100,00 \\
\hline
\end{tabular}

A depreciação foi responsável por $14 \%$ e $15 \%$ do COT, para os anos 2002 e 2003, respectivamente. Esse percentual pouco variou, visto que o produtor adquiriu poucos equipamentos e não realizou nenhuma benfeitoria. Tal fato confirma o benefício da produção de queijo, quando se aumentam as receitas sem aumento significativo nos custos.

O custo operacional efetivo foi de $\mathrm{R} \$ 17.276,60 \mathrm{e}$ $\mathrm{R} \$ 17.089,97$, para o sistema de produção que comercializa leite e o sistema de produção de queijo, respectivamente, e representou o desembolso médio no período de 24 meses. Os itens que o compõem foram divididos em grupos, cada qual responsável pelos percentuais encontrados na Tab. 3.

Quanto à mão-de-obra, o percentual zero, pode ser explicado pelo fato de o produtor utilizar somente mão-de-obra familiar. A redução dos gastos com esse item é muito importante na diminuição dos custos finais, visto que esse item representa mais de $19 \%$ do custo de produção, (Berg e Katsmam, 1998; Lopes et al., 2001; Almeida Júnior et al., 2002; Lopes et al., 2002). Ainda quanto à mão-de-obra, destaca-se na produção de queijo o aumento de uma pessoa para o trabalho de produção, o que não alterou o custo operacional efetivo, por tratar-se de mãode-obra familiar.

Não foram observadas despesas com inseminação artificial pelo fato de o produtor não adotar essa tecnologia (Tab. 3). O mesmo aconteceu com as despesas com aquisição de produtos utilizados na ordenha mecanizada. As despesas com coalho, coador, tela etc. representaram 0,16 e $0,56 \%$ das despesas para o sistema que produz queijo, em 2002 e 2003, respectivamente, enquanto as despesas exclusivas da comercialização do leite, como o INSS, por exemplo, representaram 0,44 e $0,61 \%$ das despesas nos mesmos anos citados. Um importante componente do custo de produção do leite é o frete pago para transporte até o laticínio. Nesta pesquisa, esse item não foi considerado, pois o laticínio comprador de leite remunera o produtor com um valor líquido (já descontado do frete). Nesse caso, agregar valor ao produto significa ter maiores ganhos, pois a produção de queijo não inclui gastos com INSS e frete, além de otimizar o uso da mão-de-obra familiar.

O custo total (CT), que representou a soma dos custos fixos (CF) e dos custos variáveis $(\mathrm{CV})$, foi de $\mathrm{R} \$ 16.373,72$; $\mathrm{R} \$ 16.287,94$ e $\mathrm{R} \$ 16.236,78$; $\mathrm{R} \$ 16.235,02$, para o sistema que comercializa 
leite e para o sistema que produz queijo, em 2002 e 2003, respectivamente. Pela subtração do custo total da receita (Tab. 1), observou-se que os custos variáveis do primeiro período da comercialização do leite puderam ser pagos, assim como a reserva referente à depreciação também pôde ser feita. Mas o capital investido em bens e terra não pode ser remunerado. No segundo período, ambos os sistemas tiveram seus custos variáveis pagos, bem como a reserva referente à depreciação e o capital investido em bens e terra puderam ser completamente remunerados.

Os custos fixos totalizaram $\mathrm{R} \$ 5.070,66 \mathrm{e}$ $\mathrm{R} \$ 5.131,82$, para ambos os sistemas, visto que são utilizados os mesmos equipamentos para as produções. Os utensílios utilizados unicamente para a produção do queijo foram lançados no grupo insumos para queijo. Os custos variáveis totalizaram $\mathrm{R} \$ 22.459,18$ e $\mathrm{R} \$ 22.269,32$, para o sistema que comercializa leite e o sistema que produz queijo, respectivamente. As diferenças existentes podem ser explicadas em função da diferença de atividades, nesse caso a produção de queijo requer outros produtos e utensílios para sua produção que não estão inseridos na comercialização de leite para o laticínio, como despesas com coalho e fôrma.

Os dois sistemas tiveram margem bruta e líquida positivas, evidenciando que o que foi apurado com a venda de leite ou queijo, animais e subprodutos foi suficiente para cobrir as despesas operacionais efetivas e que a atividade está remunerando a cada ciclo produtivo. Quando se analisa pelo indicador de eficiência econômica "resultado" (receita bruta menos custo total), percebe-se que, no primeiro período da comercialização do leite, o sistema apresentou resultados insatisfatórios, mostrando que a atividade leiteira não conseguiu remunerar o capital. No segundo período, o resultado apresentou $\mathrm{R} \$ 0,09$ e $\mathrm{R} \$ 0,23$, por $\mathrm{kg}$, para o sistema que comercializa leite e para o sistema que produz queijo, respectivamente (Tab. 2), evidenciando que, além de cobrir todas as despesas, o empresário conseguiu remunerar o capital em níveis acima da caderneta de poupança, não se descapitalizando.

A lucratividade foi de -19 e $13 \%$ e 7 e $28 \%$, para o sistema que comercializa leite e para o que produz queijo, nos anos de 2002 e 2003, respectivamente. Essa diferença deve-se principalmente às receitas, visto que, quanto maior a receita, maior a capacidade de pagamento de despesas.

\section{CONCLUSÕES}

O tipo de atividade pouco influenciou no custo total de produção e no "peso" dos itens que compõem o custo operacional da atividade, ao contrário das receitas, que, no caso da produção de queijo foram aumentadas significativamente. A produção e a comercialização de queijo mostraram-se mais rentáveis que a do leite, contribuindo para o aumento das receitas sem alterações significativas do custo operacional efetivo, e são uma alternativa para o incremento da renda do produtor de leite.

\section{REFERÊNCIAS BIBLIOGRÁFICAS}

ALMEIDA JUNIOR, G.A.; LOPES, M.A.; PINATTO, F. Efeito da venda de animais na rentabilidade de um sistema intensivo de produção de leite tipo B no estado de São Paulo In: REUNIÃO ANUAL DA SOCIEDADE BRASILEIRA DE ZOOTECNIA, 39., 2002, Recife. Anais... Recife: SBZ, 2002. CD-ROM.

BERG, H.V.D.; KATSMAN, T. Custos comparando despesas na produção do leite. Bol. Leite, v.5, p.3, 1998.

EMPRESA DE ASSISTÊNCIA TÉCNICA E EXTENSÃO RURAL DO ESTADO DE MINAS GERAIS - EMATER. Noticias. Disponível em: <www.emater.mg.gov.br>. Acessado em: 07 ago. 2004.

LOPES, M.A.; ALMEIDA JUNIOR, G.A.; CARVALHO, F.C. et al. Estudo da rentabilidade de um sistema de produção de leite tipo B no estado de São Paulo. In: CONGRESSO BRASILEIRO DE ADMINISTRAÇÃO RURAL, 4., 2001, Goiânia. Anais... Goiânia: ABAR, 2001. 8p. CD-ROM.

LOPES, M.A.; CAMPELLO, R.P.; CARVALHO, F.M. et al. Custo Bovino Leite 1.0: software de controle de custos para a atividade leiteira. Rev. Bras. Agroinf., v.4, p.102115, 2002. 
LOPES, M.A.; CARVALHO, F.M. Custo de produção do leite. Lavras: UFLA, 2000. 42p. (Boletim Agropecuário, 32).

LOPES, M.A.; LIMA, A.L.R.; CARVALHO, F.M. et al. Controle gerencial e estudo da rentabilidade de sistemas de produção de leite na região de Lavras (MG) Ciên. Agrotec., v.28, p.883-892, 2004a.

LOPES, M.A.; LIMA, A.L.R.; CARVALHO, F.M. et al. Efeito do tipo de sistema de criação nos resultados econômicos de sistemas de produção de leite na região de Lavras (MG). Ciên. Agrotec., v.28, p.1177-1189, 2004b.
MATSUNAGA, M.; BEMELMANS, P.F.; TOLEDO, P.E.N. et al. Metodologia de custo de produção utilizado pelo IEA. Agri. S. Paulo, v.23, p.123-139, 1976.

REIS, R.P. Introdução à teoria econômica. Lavras: UFLA/FAEPE, 1999. 108p.

SATO, R.A.C. A cadeia agroindustrial do queijo no MERCOSUL: uma simulação de custos. 1996. 71f. Dissertação (Mestrado) - Universidade Federal de Lavras, Lavras, MG. 